\title{
Modelling of freight transport flows in urban transport
}

\author{
A. Baublys \\ Transport Research Institute, \\ Vilnius Gediminas Technical University, Lithuania
}

\begin{abstract}
The topological structure of a regional urban road transport system was synthesised and the optimisation-simulation procedure of topological structure was proposed.

The synthesis of the topological structure of regional urban road transport freight systems enables an assessment of the impact of various structural characteristics on the functionality of the system. For this reason the quality of project solutions at the stage of structural system synthesis increases.

Models of optimisation and simulation (included in the simulation procedure of the optimisation of the topological structure) cover other possibilities as well. For instance, simulation models enable us to meet various functionality systems objectives, such as, for example, a comparison between the stability of the structure undergoing changes in parameters and the management of various impacts, e.g. loading technologies, etc.

Keywords: road transport freight, the simulation procedure of optimizing.
\end{abstract}

\section{Introduction}

Among other things, the technology of transportation involves the provision of services, i.e. freight haulage. Services embrace major operations (transportation or haulage) and minor procedures (loading, unloading, storage, control, documentation, etc.). The efficiency of technological operations may be defined in terms of the following factors: consumption of energy and materials per ton $/ \mathrm{km}$, and quality and intensity of hauls. Moreover, technological operations of haulage should ensure safety of goods and be environmentally friendly. 
To improve the technology of transportation may seem as simple as to replace old transport facilities with the new ones. However, even the most advanced transport facilities may not be efficiently used. Therefore, overall technological processes of transportation should be improved. To achieve this, numerous tests should be conducted, involving the determination of flows of goods, their constant control and forecasting, road network and traffic optimization, etc. The problems of improving freight transportation in long hauls and carriage of 20-40 tons of goods were analysed in [1-4]. However, the analysis of carriage of goods of 50-1500 kg over small areas by transport facilities, say in the city, with the bottlenecks on the roads and ecological limitations in force, has not been practically made. In the present investigation, some solutions to the above problems are offered.

\section{Synthesis of the topological structure of road freight transport regional system (KKTRS)}

In designing a logistical center for transport distribution, the topological structure of the area that is serviced by this centre should be ascertained. In a KKTRS, a number of local warehouses, their capacity and location in the zone as well as the particular urban areas that will be serviced by the particular warehouses (for instance, by those belonging to a commercial enterprise "MAXIMA"), should be provided for.

For example, the network of the urban roads for freight transportation is expressed by the matrix $D=\left\|d_{i i^{\prime}}\right\|$, where $d_{i i^{\prime}}$ are the shortest routes in the road network between the $i$-th and the $i^{\prime}$-th points; $d_{i i^{\prime}}=d_{i^{\prime} i}$. The amount of goods to be carried in the particular region serviced by the particular company is also determined by the matrix $A^{K}=\left\|a_{i i^{\prime}}\right\|$, where $a_{i i^{\prime}}$ is the flow of goods from point $i$ to point $i^{\prime}$. The purpose of the topological synthesis of freight road transport system embracing a set of commercial enterprises in the region $E^{n}$, the route between the points $D$ and the flow of goods $A^{k}$, is to divide the settlements of a region into zones serviced by the warehouses $E_{j}\left(\bigcup_{j} E_{j}=E^{n}, E_{j} \cap E_{j^{\prime}}=\varnothing\right)$ and to determine the location of warehouses within zones $E_{t}$, minimizing the costs of goods transportation in the region. This is expressed in the following way:

$$
\begin{gathered}
\sum_{j \in J} \sum_{i \in I} \sum_{i^{\prime} \in I} c_{1} d_{i i^{\prime}} x_{i j} x_{i^{\prime} j^{\prime}}+\sum_{j \in J} \sum_{j^{\prime} \in J} \sum_{k \in I} \sum_{k^{\prime} \in I} c_{2} d_{k k^{\prime}} y_{k j} y_{k^{\prime} j^{\prime}} \\
+\sum_{i \in I} \sum_{i^{\prime} \in I} a_{i i^{\prime}} x_{i j} x_{i^{\prime} j^{\prime}}+\sum_{j \in J} \sum_{j^{\prime} \in J} \sum_{k \in I} \sum_{k^{\prime} \in I_{j}} c_{1} d_{k k^{\prime}} y_{k^{\prime} j}+\sum_{i \in I_{j} i^{\prime} \in I_{j}} \sum_{i i^{\prime}} x_{i j} x_{i^{\prime} j^{\prime}},
\end{gathered}
$$

here, $x_{i j}=1$ if the point $i$ enters zone $j$ of the warehouse; in the opposite case $x_{i j}=0 ; y_{i j}=1$, if the warehouse is located at the point $i$; for the opposite case 
- $y_{i j}=0 ; c_{1}-$ cost of goods transportation by low or medium functional capacity vehicles; $c_{2}$ - cost of transportation by high functional capacity lorries and trailers; $J$ - a set of warehouse indices; $I_{j}$ - a set of indices of settlements in the $j$-th warehouse zone; $N$ - a set of indices of the region settlements where warehouses may be located.

The first term in the formula (1) expresses the cost of goods transportation within a zone, while the 2 nd term denotes the cost of goods transportation from one warehouse to another, and the 3-d - the cost of goods carriage to and from the warehouse.

The synthesis of the topological structure of freight road transport regional system is performed by solving two problems:

a) the distribution of a set of points supplying and receiving goods according to zones serviced by the particular warehouses, minimizing the total freight flows disbalance between the warehouses;

b) determining the location of the warehouse within a zone, minimizing the total volume of work of delivering goods to a warehouse and taking them out of it. The total imbalance of cross-hauls will be the optimization criterion of the problem $a$, because this is the main reason why the functional capacity of vehicles and the hauls are not used to full advantage.

Let $P_{i}=\left\{E_{i / j}=\overline{1,2^{n}}\right\}$ be a family of all $E_{j}$ subsets of a region set of points $E^{P}=\{1,2, \ldots, i, \ldots, n\}$. Here, $n$ is the number of points in the region. In order to explain the $k$-th expansion of the set $E^{P}$, let us introduce the set $J_{k}$ which is such a set with the index $E_{j}$ that $\bigcup_{j \in J_{k}}=E^{P}, E_{j} \cap E_{j^{\prime}}=\varnothing, V_{j}, j^{\prime} \in J_{K}$.

Then, the $k$-th expansion of the set $E^{P}$ is such a subfamily $P_{k}\left(P_{k} \subset R\right)$ that $P_{k}=\left\{E_{j} / j \in J_{k}\right\}$, where $J_{k}$ means a subset $E_{j}$ of the expansion. The imbalance of cross-flows of goods of the warehouse of the zone serviced by the warehouse $j$ will be as follows:

$$
\alpha_{j}=\left|\sum_{i \in E_{j}} \sum_{i^{\prime}=E_{j}}\left(a_{i i^{\prime}}-a_{i^{\prime} i}\right)\right|,
$$

here, $a_{i i^{\prime}}$ is the flow of goods from point $i$ to point $i^{\prime}$.

The total imbalance among the warehouses in the system for the k-th expansion is determined in the following way:

$$
z=\sum_{j \in J} \alpha_{j} x_{j},
$$


here, $x=\left\{\begin{array}{l}1, \text { if } j \in J_{k}, \\ 0, \text { if } j \notin J_{k},\end{array}\right.$ where $J$ is a set of indices of the subset $E_{j}$, the potential zones serviced by warehouses.

In formalizing the problem of the system's structure synthesis, the requirements to structural and functional KKTRS parameters are stated by the constraints of two types: 1) the constants of structural parameters of the system are commonly expressed by the analytical expression; 2) algorithmic expression is mostly used for functional parameters requirements (the sophisticated relationships of these parameters can not be expressed analytically).

The following analytically expressed constraints can be suggested:

The requirements that the subsets do not cross each other and cover the whole sets of the region points:

$$
\begin{gathered}
\sum_{j \in J} t_{i j} x_{j}=1, \quad i \in E^{P}, \\
t_{i j}=\left\{\begin{array}{l}
1, \text { if } i \in E_{j}, \\
0, \text { if } i \notin E_{j} .
\end{array}\right.
\end{gathered}
$$

here,

The number of the region warehouses serviced is:

$$
Q_{\min }^{t} \leq \sum_{j \in J} x_{j} \leq Q_{\max }^{t}
$$

here, $Q_{\min }^{t}, Q_{\max }^{t}-$ permissible and maximum numbers of warehouse zones in the system for the warehouse number in each zone:

$$
\sum_{i \in E^{P}} b_{i} t_{i j} \geq 1, \quad j \in J
$$

here, $b_{i}=\left\{\begin{array}{l}1, \text { if a warehouse may be set up in point } i, \\ 0 \text { - for the opposite case; }\end{array}\right.$

$$
G_{\min }^{l} \leq \sum_{i \in E^{P}} t_{i j} \leq G_{\max }^{l}, \quad j \in J
$$

here, $G_{\min }^{l}, G_{\max }^{l}-$ permissible minimum and maximum numbers of points in a warehouse zone:

$$
d_{i i^{\prime}} t_{i j} t_{i^{\prime} j} \leq L^{l}, \forall i, i^{\prime} \in E^{P}, j \in J
$$

for the length of the route between warehouse $j$ and the points of its zone:

$$
d_{i i^{\prime}} \leq L_{T}^{l}, \forall \dot{t}^{\prime}: b_{i^{\prime} j}=1, \quad j \in J, \quad i \in E^{P},
$$


here, $L_{T}^{l}$ is the permissible length of route between the warehouse $j$ and the points of its zone; the total volume of goods in a flow handled in warehouse $j$ :

$$
\sum_{i \in E^{P}} \sum_{i \in E^{P}}\left(a_{i i^{\prime}}+a_{i^{\prime}}\right) t_{i j}\left(1-t_{i j}\right) \leq \hat{P}_{j}, \quad j \in J,
$$

here, $\hat{P}_{j}$ - the capacity of the terminal $j$ allowing one to handle goods in the period of time $\tau_{m}$.

Algorithmic restrictions identified for

- the coefficient of carrying capacity

$$
k_{k}\left(P_{k}, N_{A}, A^{g}, D, N_{j}^{p r m}\right)>k_{k}^{n} ;
$$

- the coefficient of run exploitation

$$
k_{r}\left(P_{k}, N_{A}, A^{g}, D, N_{j}^{p r m}\right) \geq k_{r}^{n} ;
$$

- for the term of goods delivery

$$
T_{m}\left(P_{k}, N_{A}, A^{g}, D, N_{j}^{p r m}\right) \leq T^{n}
$$

- the amount of time the good stay in the warehouse

$$
\tau_{m j}\left(P_{k}, N_{A}, A^{g}, D, N_{j}^{p r m}\right) \leq \tau^{n}, \forall m \in M ;
$$

- average technical speed of road vehicles

$$
V_{\text {tech. }}\left(P_{k}, N_{A}, A^{g}, D, N_{j}^{p r m}\right) \leq V_{\max }^{n},
$$

here $K_{k}$ and $K_{k}^{n}$ are real and normative coefficients of carrying capacity; $K_{r}$ and $K_{r}^{n}$ real and normative coefficients of run exploitation; $T_{m}$ and $T_{m}^{n}$ real and normative terms of delivery of goods; $M$ - set of indices of goods consignments; $V_{\text {tech. }}$ and $V_{\text {tech. }}^{n}$ real and normative average technical speed of road vehicles; $\tau_{m j}$ - real time of the consignment $m$ goods stay in the $j$ warehouse; $\tau^{n}$ normative time of stay of goods in the warehouse; $N_{A}$ - set of vehicles' characteristics (number of vehicles, their owner dependence, etc.); $A^{g}$ 
- the matrix of freight flows of the region, $A^{g}=\left\|a_{i^{\prime}}\right\| ; D$ - the matrix of distances between the points in the region, $D=\left\|d_{i i^{\prime}}\right\| ; N_{j}^{p r m}$ - the number of handling places in the warehouse $j$.

Thus the problem $a$ - the distribution of points of the regional set into the servicing zones of the warehouses - is solved by the minimisation of the final function (3), when there are constraints (4)-(15).

For the formalisation of the problem $b$ the term overall freight operation is introduced for the incoming and outgoing goods into the zone of the warehouse $j$ established in the point $i$. It is defined as follows:

$$
\begin{aligned}
& \beta_{i j}=\sum_{i^{*} \in E^{P}} \sum_{i^{\prime} \in E^{P}}\left(a_{i^{*} i^{\prime}}+a_{i^{\prime} i^{*}}\right) d_{i i^{\prime}} t_{i^{\prime} j}\left(1-t_{i^{*} j}\right), \\
& j \in J_{k}, \quad i: b_{i}=1 .
\end{aligned}
$$

The problem $b$ is formulated as follows:

$$
\begin{aligned}
& \sum_{j \in J_{k}} \sum_{i \in E_{j}} \beta_{i j} y_{i j} \rightarrow \min , \\
& y_{i j}=\left\{\begin{array}{l}
1, \text { if the warehouse } j \text { is established in the point } i ; \\
0 \text { for the opposite case; }
\end{array}\right.
\end{aligned}
$$

when there are constraints of:

- the number of warehouses in each zone

$$
\sum_{i: b_{i}=1} y_{i j}=1, \quad j \in J_{k}
$$

- permissible route distance between the warehouses in the region

$$
\begin{aligned}
& L_{\min } \leq d_{i i^{\prime}} y_{i j} y_{i^{\prime} j^{\prime}} \leq L_{\max }, \quad i \in E_{j}, \quad i^{\prime} \in E_{j^{\prime}}, j, \\
& j^{\prime} \in J_{k} .
\end{aligned}
$$

As mentioned before, the model of the synthesis of the topological structure (3)-(15), besides the constraints (4)-(10), (17)-(18), which are the analytical functions of the structural elements of the system, also comprises the constraints (11)-(15), which are complex functions of structural and functional characteristics and are defined in the algorithmic form. These constraints indicate essential dynamic aspects of the projected systems and its elements functioning and they can be defined by the way of simulation modelling of discrete developments.

Thus the model of the analysed structure synthesis will be as follows:

$$
F(\bar{X}) \rightarrow \operatorname{extr}, \bar{X} \in \sigma,
$$


here $\sigma=\bar{\sigma} \cap \overline{\bar{\sigma}}, \bar{\sigma}, \overline{\bar{\sigma}}$ the set of structure variants allowed according to the analytical and algorithmic constraints.

The optimisational simulation procedure was developed enabling the use of optimisation and simulation models jointly for finding analytical variants of the structure.

Below certain data of modelling results are presented.

The results obtained by way of modelling are presented in Table 1 and Table 2 and in Figures 1(a), (b), (c), and (d).

Table 1: Distribution laws of stochastic variable meanings.

\begin{tabular}{|l|c|c|c|c|c|}
\hline \multirow{2}{*}{ Stochastic variable } & \multirow{2}{*}{$\begin{array}{c}\text { Distribution } \\
\text { law }\end{array}$} & \multicolumn{4}{c|}{ Parameters of distribution law } \\
\cline { 3 - 6 } & & Average & $\begin{array}{c}\text { Least } \\
\text { meaning }\end{array}$ & $\begin{array}{c}\text { Highest } \\
\text { meaning }\end{array}$ & $\begin{array}{c}\text { Standard } \\
\text { digression }\end{array}$ \\
\hline Type of goods & Uniform & 2.5 & 1.0 & 4.0 & - \\
\hline Size of goods' consignment & Puasson's & 7.0 & 1.0 & 25.0 & - \\
\hline $\begin{array}{l}\text { Time of delivery of goods' } \\
\text { consignment }\end{array}$ & Puasson's & 12.0 & 0 & 24.0 & - \\
\hline Duration of vehicle handling & Normal & 1.0 & 0.8 & 1.15 & 0.15 \\
\hline Vehicle traffic speed & Normal & 50.0 & 45.0 & 55.0 & 5.0 \\
\hline $\begin{array}{l}\text { Number of goods' consignment } \\
\text { delivered to the warehouse No 1 }\end{array}$ & Puasson's & 80.0 & 40.0 & 200.0 & - \\
\hline $\begin{array}{l}\text { Number of goods' consignment } \\
\text { delivered to the warehouse No 2 }\end{array}$ & Puasson's & 60.0 & 30.0 & 140.0 & - \\
\hline $\begin{array}{l}\text { Number of goods' consignment } \\
\text { delivered to the warehouse No 3 }\end{array}$ & Puasson's & 60.0 & 30.0 & 140.0 & - \\
\hline $\begin{array}{l}\text { Number of goods' consignment } \\
\text { delivered to the warehouse No 4 }\end{array}$ & Puasson's & 130.0 & 90.0 & 350.0 & - \\
\hline
\end{tabular}

Table 2: $\quad$ Results obtained by modelling.

\begin{tabular}{|l|c|c|c|c|}
\hline \multirow{2}{*}{ Variables } & \multicolumn{4}{c|}{ Names of locations of warehouses } \\
\cline { 2 - 5 } & Vilnius & Kaunas & Klaipeda & Šiauliai \\
\hline Quantity of consigned goods, thousand t & 62.4 & 40.0 & 52.7 & 56.2 \\
\hline Quantity of outgoing goods, thousand t & 58.7 & 38.1 & 56.1 & 58.8 \\
\hline Amount of loaded vehicles & 694 & 557 & 460 & 640 \\
\hline Amount of consigned vehicles without goods & 71 & 118 & 120 & 54 \\
\hline Amount of unloaded vehicles & 563 & 441 & 487 & 564 \\
\hline Average loading coefficient & 0.64 & 0.54 & 0.72 & 0.65 \\
\hline Average time of goods stay in warehouse, $\mathrm{h}$ & 64.2 & 45.8 & 44.8 & 109.2 \\
\hline Average time of vehicle queuing, $\mathrm{h}$ & 0 & 0 & 0.53 & 0.09 \\
\hline Average number of queuing vehicles & 0 & 0 & 0.42 & 0.04 \\
\hline Maximum number of queuing vehicles & 0 & 0 & 3.0 & 1.0 \\
\hline
\end{tabular}




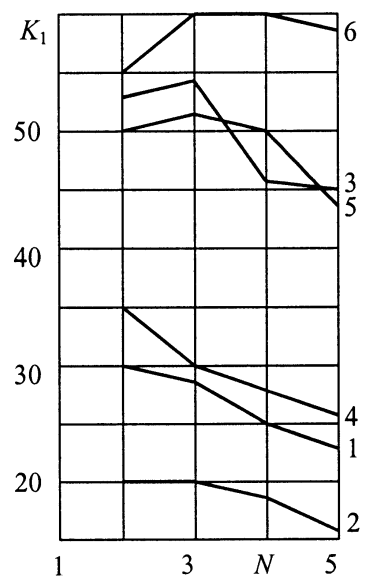

(a)

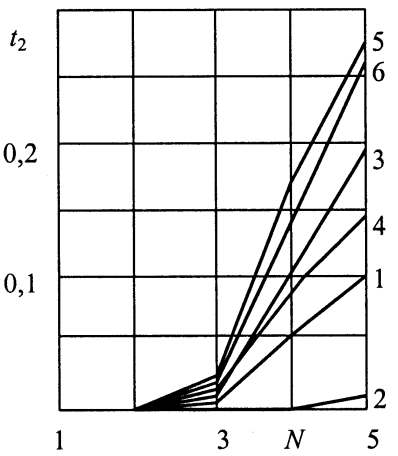

(c)

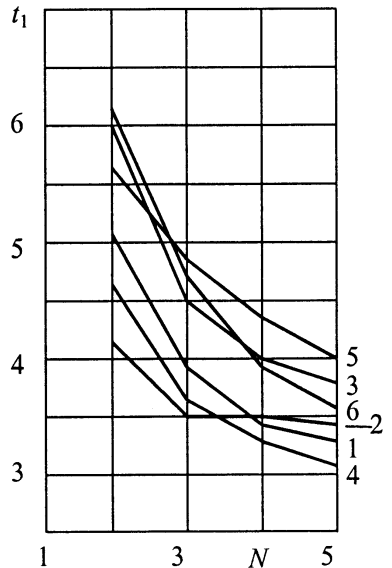

(b)

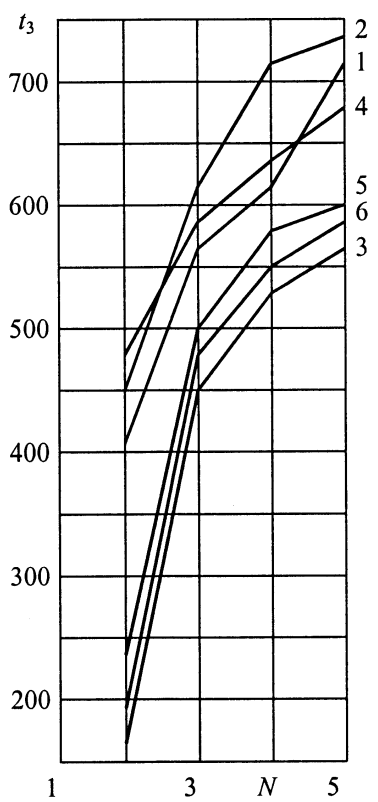

(d)

Figure 1: $\quad$ Results obtained by modelling.

This data makes it possible to gauge the impact of different structural characteristics of the system on its functioning, thus improving the quality of the project solutions in the stage of the synthesis of the system's structure.

The size of the goods' consignment is a random quantity distributed according to the law with mathematic probability of $0.5 \mathrm{t}$ and with a standard digression of $0.1 \mathrm{t}$. The average speed of the vehicle is a normal random quantity 
with the mathematic probability of $50 \mathrm{~km} / \mathrm{h}$ and with a standard digression of 1.7 $\mathrm{km} / \mathrm{h}$.

The formulated problem model concerning the distribution of freight flows in the transport terminal to the consumers makes it possible to gauge the vehicle's specifications (dimensions, carrying capacity), limitations of delivery time, the time resources of the vehicle and general costs.

\section{Conclusion}

1. In big cities (Vilnius, Kaunas, etc.), large chains of stores should constantly study the flow of their goods as well as the flow of transport facilities delivering these goods to trade outlets and warehouses. Institutions of local government should control it and stimulate their interest in rational solutions to these problems.

2. The synthesis of the topological structure of the regional urban road freight transport system makes it possible to evaluate the impact on the functioning of the system, which is stipulated by the characteristics of the various structural systems. thus it is possible to improve the quality of project solutions at the synthesis stage of the system's structure.

3. Optimisation and simulation models included in the simulation procedure of the topological structure's optimisation give rise to other possibilities as well. For example, the simulation model makes it possible to solve different problems related to the analysis of the system's functionality, such as investigation of the system's stability after changes to its parameters, and the comparative analysis of efficiency of different types of ruling impacts, such as carrying, loading, handling technologies, etc.

4. The algorithm for the optimal carrying capacity of the vehicle fleet has been developed, which enables the carrier to find a required average listing number of vehicles according to the carrying capacity.

5. Methods for defining the optimal size of the consignment of goods and selection of transportation type has been proposed, when the general storage and transportation costs are selected as the optimum criteria.

6. The algorithm for the optimisation of the local road network among the trade points has been developed. Testing of the algorithm proved that in the case when the density of the distribution of target functions' meanings in the extremum zone is sufficiently large, the independent random search is sufficiently efficient even if compared with regular methods. Firstly, the number of the variants analysed is $200-500$. Secondly, many variants close to the global extremum are discovered, which in most cases can be interpreted as an indeterminacy zone after later evaluation of incomprehensive initial information. Generally such a zone is found out by way of multi-critical optimisation through the application of regular methods. 


\section{References}

[1] Guelat, J., Florian, M. \& Crainic, T.-G. A Multimode Multiproduct Network Assignment Model for Strategic Planning of Freight Flows. Transportation Science. Vol 24, No 1. February, pp. 25-39, 1990.

[2] Zhan, F.-B. \& Noon, Ch.-E. Shortest Path Algorithms: An Evaluation using Real Road Networks. Transportation Science. Vol 32, No 1. February, pp. 65-73, 1998.

[3] Nuzzolo, A., Russo, F. \& Crisali, U. A Doubly Dynamic Schedule based Assignment Model for Transit Network. Transportation Science. Vol 35, No 3. August, pp. 268-285, 2001.

[4] Bodin, L., Mingozzi, A., Baldacci, R. \& Ball, M. The Roll on Roll off Vehicle Routing Problem. Transportation Science. Vol 34, No 3, August, pp. 256-271, 2000.

[5] Baublys, A. Assessment of statistical probability of the technological transportation process. TRANSPORT, Vol XVII, No 4, Vilnius, Technika, pp. 147-151, 2002. 